\title{
Metachronous Osteoid Osteoma Thirty-Four Years Later: Case Report
}

\section{Caff Giuseppe*, Campanacci Domenico Andrea and Capanna Rodolfo}

Department of Orthopaedic Oncology, Azienda Ospedaliero-Universitaria Careggi, Largo Palagi 1, 50139 Firenze, Italy

\begin{abstract}
In international literature, several cases of multicentric osteoid osteoma have been described. Clinical presentations with a double nidus in the same bone, in adjacent bones or in symmetric bones have been reported. In the present study the authors report a case of an osteoid osteoma of the right distal femur in a forty-five years old man with a history of osteoid osteoma of the left distal femur treated thirty-four years earlier. To our knowledge, only two similar cases were known so far.
\end{abstract}

\section{Introduction}

The Osteoid Osteoma (OO) is a benign osteoblastic bone tumour, firstly described by Jaffe in 1935 [1]. It usually arises in long bones of children and young adults, but the localization in the spine [2] or in short a bone is not unfrequent [3-5].

Osteoid osteomas having radiologic and clinical features other than classical presentation of osteoid osteoma are called atypical osteoid osteomas. Atypical osteoid osteomas are important because the diagnosis and treatment are often complicated in these cases [6].

The objective of the present report was to describe a particular case of Osteoid Osteoma of the right distal femur in a forty-five years old man with a history of Osteoid Osteoma of the left distal femur thirty-four years before. In international literature many cases of multicentric or double nidus Osteoid Osteoma and few cases of Osteoid Osteoma with double localization in the same bone, in adjacent bone, in symmetric bone and only three cases in different bone were described [7].

\section{Case Report}

A forty-five years old man complaining pain to the right knee referred to our Institute for an orthopeadic consultation in february 2011. The history revealed he had been treated for an Osteoid Osteoma of the left distal femur in 1977. From the review of the old medical records resulted that, in october 1977, the patient referred to an orthopaedic department, complaining persistent pain at the medial site of the left knee from one year. Pain had gone to remission after NSAIDs' assumption. A standard X-ray of the left femur was performed, showing a localized area in the medial condyle with swelling of the cortex and periosteal reaction. A stratigraphy to localize the lesion was performed and, according to the peculiar clinical and radiological findings, the diagnostic hypothesis was osteoid osteoma. The clinical examination reports of a slight swelling of the knee with normal range of motion and moderate quadriceps muscle's hypotrophy. Pain after palpation in correspondence of the medial condyle was observed. The patient was treated with surgical excision of the lesion and, two days later, he was resigned with resolution of pain. Macroscopically, the lesion was described as a sclerotic zone of mature bone and the histologic diagnosis was osteoid osteoma. No complications were observed and at follow up of one, two and six months, the patient was completely asymptomatic.

Thirty-four years later, on February 2011, the patient complained a continuous, deep and intense pain at the right knee, increasing during the night, but completely disappearing after oral assumption of NSAIDs. Standard X-Ray of the femur and tibia, showed a subperiosteal area of sclerosis, proximal to the medial condyle. The CT scan (Figure1) showed an area of cortical thickening in the postero-medial region of the metaphysis (black arrow), with an extension length in sagittal plane of $41 \mathrm{~mm}$, width in frontal plane of $31 \mathrm{~mm}$ and depth of $12 \mathrm{~mm}$; a central osteolytic nidus of $5 \mathrm{~mm}$ (white arrow) was also described. A bone scan (Figure 2) pointed out the presence of an area of evident increase of uptake corresponding to the medial cortex of the distal right femur.

The imaging pattern was consistent with the diagnosis of osteoid osteoma.

The patient underwent radiofrequency ablation of the Osteoid Osteoma under CT control, using RITA probe with timing of three minutes at $90^{\circ} \mathrm{C}$ and then one minute at $95^{\circ} \mathrm{C}$ (Figure 3). Before thermoablation of the lesion, a needle biopsy was performed, confirming the clinical and radiological diagnosis of osteoid osteoma. The postoperative day the patient was resigned and at follow up after one and six months he was completely asymptomatic.

\section{Discussion}

The purpose of this report was to describe an atypical case of metachronous osteoid osteoma of the right distal femur in a forty-five years old man with a history of osteoid osteoma of the left distal femur thirty-four years before.

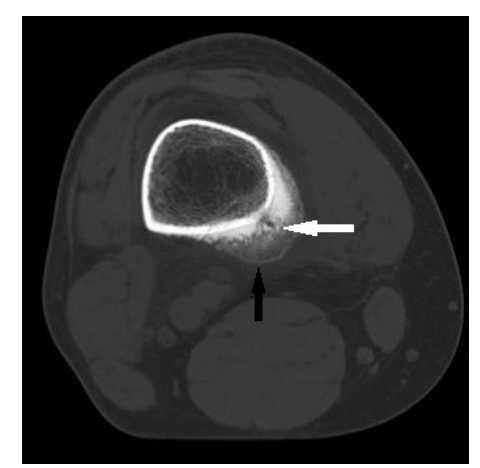

Figure 1: Axial computed tomography section confirming a clearly defined lucent nidus (white arrow) with surrounding sclerotic rim (black arrow).

*Corresponding author: Caff Giuseppe, Department of Orthopaedic Oncology, Azienda Ospedaliero-Universitaria Careggi, Largo Palagi 1, 50139 Firenze, Italy, E-mail: giuseppe.caff@gmail.com

Received November 15, 2013; Accepted December 27, 2013; Published December 30, 2013

Citation: Giuseppe C, Andrea CD, Rodolfo C (2013) Metachronous Osteoid Osteoma Thirty-Four Years Later: Case Report. J Clin Case Rep 4: 327. doi:10.4172/2165-7920.1000327

Copyright: (c) 2013 Giuseppe C, et al. This is an open-access article distributed under the terms of the Creative Commons Attribution License, which permits unrestricted use, distribution, and reproduction in any medium, provided the original author and source are credited. 


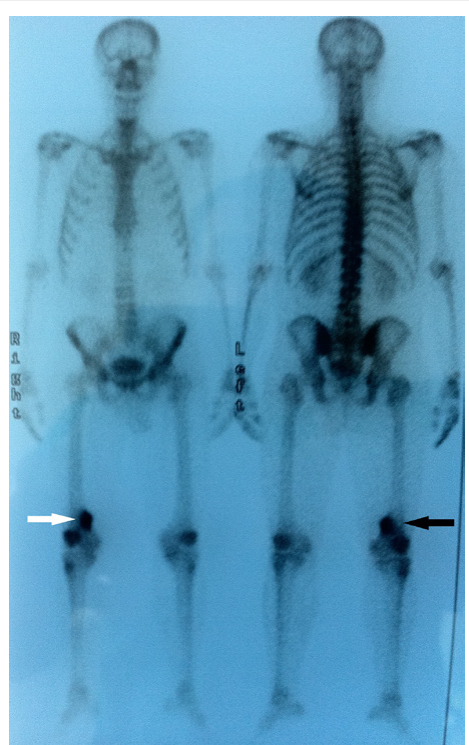

Figure 2: Bone Scan demonstrating corresponding focal hot spot in anterior (white arrow) and posterior (black arrow) projection.

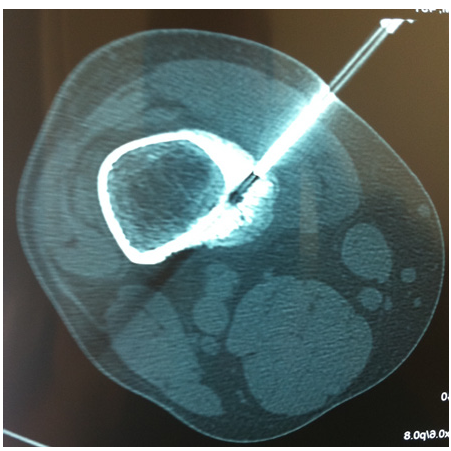

Figure 3: Axial computed tomography section with radiofrequency ablation (RFA) needle placed within the drilled tract.

A review of the international literature showed several cases of Osteoid Osteoma with multicentric or double nidus close to each other [8-30]. Multiple nidi may be present close to each other in a single bone or in adjacent bones or may be present in separate bones in multicentric lesions. The latter is much rarer and usually called as metachronous osteoid osteoma [6].

Allieu et al., in his case achieved the definitive diagnosis of double Osteoid Osteoma one year later, due to the persistence of pain [31]. Mazurek and Zeitek described one case of synchronous double localization of Osteoid Osteoma in the same bone [32]. Five cases of Osteoid Osteoma in two adjacent bones were reported: the presentation of the two lesions was synchronous in 4 cases [33-36] and metachronous (after one year) in one case [37].

Gonzalez et al. have stated that, the limited number of multicentric osteoid osteoma cases in the literature is an underestimation, because the multicentricity of the lesion may be missed [14].

Four cases of bilateral, symmetric and synchronous Osteoid Osteoma were described in literature. Fagerberg et al. in 1955 [38] and Botella in 1958 [39] reported two cases where the lower ends of the femurs was affected. Sluga et al. [40] treated a patient with two Osteoid
Osteoma arising in right and left radius. A bilateral Osteoid Osteoma of the mandible was reported by Duenas et al. [41]. Yildiz et al. [42] included in his series a case of Osteoid Osteoma involving the left tibia and, one month later, the right tibia.

Multiplicity of the nidi in osteoid osteoma is not well explained [6]: some authors suggest that multicentric osteoid osteoma is a borderline form of osteoid osteoma that transforming into an osteoblastoma [4345] while Byers assessed that osteoid osteoma and osteoblastoma are two distinct entities [46]. Differently, Zmurko et al. [44] and Beck et al. [47] have stated that multicentric osteoid osteoma may represent an incomplete attempt at healing that resulted in the walling off of the first nidus and the subsequent formation of two distinct nidi.

Only two cases similar to our report were described. Rand et al described a case of an Osteoid Osteoma in the distal phalanx of the left index finger and, thirteen years later in the femoral neck of the right hip [48]. Beck et al. in 2011 reported a case of an Osteoid Osteoma of the tibia and of T7 vertebral body [47].

\section{Conclusion}

Our case indicates that a second osteoid osteoma can rarely occur in a different bone in the same patient, even many years later. In case of a patient with a history of a previous osteoid osteoma, presenting with deep and continuous pain in a different site, increasing during the night and relieved by oral assumption of Non-Steroidal Anti-Inflammatory Drugs (NSAIDs), an accurate evaluation of the radiographic findings is recommended because a metachronous osteoid osteoma is a possible diagnosis.

No basis was reported in literature to assess a possible genetic predisposition for these rare and particular presentations of osteoid osteoma. Nevertheless, considering its extremely rare incidence, a metachronous osteoid osteoma in a different bone in the same patient must be considered an occasional event.

\section{References}

1. Jaffe HL (1935) Osteoid-osteoma: a benign osteoblastic tumour composed of osteoid and atypical bone. Arch Surg. 31: 709-728.

2. Gasbarrini A, Cappuccio M, Bandiera S, Amendola L, van Urk P, et al. (2011) Osteoid osteoma of the mobile spine: surgical outcomes in 81 patients. Spine (Phila Pa 1976) 36: 2089-2093.

3. Hattori H, Takase K, Morohashi A (2011) Osteoid osteoma of the great toe. Orthopedics 34: e432-435.

4. Gürkan V, Orhun H, Bülbül M, Kayahan S (2011) Osteoid osteoma of the cuboid bone: a rare cause of foot pain. Acta Orthop Traumatol Turc 45: 66-69.

5. Le Corroller T, Champsaur P (2011) Osteoid osteoma of the midfoot percutaneous radiofrequency treatment in 2 cases. J Foot Ankle Surg 50: 754-757.

6. Ciftdemir M, Tuncel SA, Usta U (2013) Atypical osteoid osteomas. Eur J Orthop Surg Traumatol.

7. Amendola L, Cappuccio M, De lure F (2013) Multicentric osteoid osteoma in C5 vertebra and parietal bone. Spine J 13: 1960-1961.

8. Rosenthal DI, Hornicek FJ, Wolfe MW, Jennings LC, Gebhardt MC, et al. (1998) Percutaneous radiofrequency coagulation of osteoid osteoma compared with operative treatment. J Bone Joint Surg Am 80: 815-821.

9. Aynaci O, Turgutoglu O, Kerimoglu S, Aydin H, Cobanoglu U (2007) Osteoid osteoma with a multicentric nidus: a case report and review of the literature. Arch Orthop Trauma Surg 127: 863-866.

10. Buluc L, Akansel G, Arslan A, Sarlak AY, Tosun B (2008) Synchronous multicentric osteoid osteoma with associated fibrous cortical defect Orthopedics 31: 95.

11. Calderoni P, Gusella A, Martucci E (1984) Multiple osteoid osteoma in the 7th dorsal vertebra. Ital J Orthop Traumatol 10: 257-260. 
12. Glynn JJ, Lichtenstein L (1973) Osteoid-osteoma with multicentric nidus. A report of two cases. J Bone Joint Surg Am 55: 855-858.

13. Goidanich L, Battaglia L (1958) Neoplasia benigna di tessuto osteoblastica Chir Organi Mov 46:353-388.

14. Gonzalez G, Abril JC, Mediero IG, Epeldegui T (1996) Osteoid osteoma with a multicentric nidus. Int Orthop 20: 61-63.

15. Greenspan A, Elguezabel A, Bryk D (1974) Multifocal osteoid osteoma. A case report and review of the literature. Am J Roentgenol Radium Ther Nucl Med 121: 103-106.

16. Kenan S, Abdelwahab IF, Klein MJ, Hermann G, Lewis MM (1994) Case report 864. Elliptical, multicentric periosteal osteoid osteoma. Skeletal Radiol 23: 565568

17. Keret D, Harcke HT, MacEwen GD, Bowen JR (1989) Multiple osteoid osteomas of the fifth lumbar vertebra. A case report. Clin Orthop Relat Res : 163-168.

18. Kaul D, Bonhomme O, Schwabe P, Gebauer B, Streitparth F (2013) Osteoid Osteoma with a Multicentric Nidus: Interstitial Laser Ablation under MRI Guidance. Case Rep Orthop 2013: 254825.

19. Lapidus PW, Salem EP (1949) Osteoid osteoma; report of a case with probable double lesion. Arch Surg 58: 318-327.

20. Matera D, Campanacci DA, Caldora P, Mazza E, Capanna R (2005) Osteoid osteoma of the femur with a double nidus: a case report. Chir Organi Mov 90: 75-79

21. Meary R, Merle d'Aubigné R, Mazabraud A (1965) [Benign osteoblastomas] Mem Acad Chir (Paris) 91: 911-925

22. Messoudi A, Fnini S, Labsaili N, Ghrib S, Rifki A, et al. (2007) [Two osteoid osteomas in the same lunate]. Chir Main 26: 146-149.

23. Miyazaki M, Miyazaki A, Kurabayashi T, Shinozaki T, Endo K, et al. (2012) CT fluoroscopy-guided radiofrequency ablation of osteoid osteoma with double nidi. Jpn J Radiol 30: 78-80

24. Muren C, Höglund M, Engkvist O, Juhlin L (1991) Osteoid osteomas of the hand. Report of three cases and review of the literature. Acta Radiol 32: 62-66.

25. Nelson MC, Lack EE, Freedman MT (1994) Case report 856: Multifocal osteoid osteoma in a 2.5-year-old child. Skeletal Radiol 23: 465-467.

26. Schai P, Friederich N, Krüger A, Jundt G, Herbe E, et al. (1996) Discrete synchronous multifocal osteoid osteoma of the humerus. Skeletal Radiol 25: 667-670.

27. Schajowicz F, Lemos C (1970) Osteoid osteoma and osteoblastoma. Closely related entities of osteoblastic derivation. Acta Orthop Scand 41: 272-291.

28. Solarino G, Scialpi L, De Vita D, Cimmino A (2004) Multiple osteoid osteoma. A clinical case. Chir Organi Mov 89: 161-166.

29. Tamam C, Yildirim D, Tamam M (2009) Multicentric osteoid osteoma with a nidus located in the epiphysis. Pediatr Radiol 39: 1238-1241.
30. Uehlinger E (1977) [Multicentric osteoid osteoma of the tibial shaft with atypica radiographic image]. Arch Orthop Unfallchir 89: 101-107.

31. Allieu Y, Lussiez B, Benichou M, Cenac $P$ (1989) A double nidus osteoid osteoma in a finger. $\mathrm{J}$ Hand Surg Am 14: 538-541.

32. Mazurek T, Zietek A (2003) [Double localization of osteoid osteoma of the tibia-case report]. Chir Narzadow Ruchu Ortop Pol 68: 349-351.

33. Alcalay M, Clarac JP, Bontoux D (1982) Double osteoid-osteoma in adjacent carpal bones. A case report. J Bone Joint Surg Am 64: 779-780.

34. Keim HA, Reina EG (1975) Osteoid-osteoma as a cause of scoliosis. J Bone Joint Surg Am 57: 159-163.

35. O’Dell CW Jr, Resnick D, Niwayama G, Goergen TG, Linovitz RJ (1976) Osteoid osteomas arising in adjacent bones: report of a case. J Can Assoc Radiol 27: 298-300.

36. Resnick D (1982) Double osteoid-osteoma in adjacent carpal bones. J Bone Joint Surg 64:1399.

37. Larsen LJ, Mall JC, Ichtertz DF (1991) Metachronous osteoid-osteomas Report of a case. J Bone Joint Surg Am 73: 612-614.

38. Fagerberg S, Falkmer S, Ploman L (1955) Osteoid osteoma; a case with bilateral, symmetric lesions. Acta Soc Med Ups 60: 235-245.

39. Botella A (1958) [A case of bilateral, symmetrical osteoid osteoma of the lower ends of the femurs]. J Radiol Electrol Arch Electr Medicale 39: 901-903.

40. Sluga M, Windhager R, Pfeiffer M, Dominkus M, Kotz R (2002) Peripheral osteoid osteoma. Is there still a place for traditional surgery? J Bone Joint Surg Br 84: 249-251.

41. Dueñas GR, Cervantes AA, Abitia DHE, Walle NAA, Lesso ADF (2005) Osteoma Osteoide mandibular bilateral: reporte de caso. Revista de Ciencias Clínicas (México): 39-47

42. Yildiz Y, Bayrakci K, Altay M, Saglik Y (2001) Osteoid osteoma: the results of surgical treatment. Int Orthop 25: 119-122.

43. Chiou YY, Rosenthal DI, Rosenberg AE (2003) "Beaded" osteoid osteoma: a possible transition between solitary and multicentric tumor. Skeletal Radiol 32 412-415.

44. Zmurko MG, Mott MP, Lucas DR, Hamre MR, Miller PR (2004) Multicentric osteoid osteoma. Orthopedics 27: 1294-1296.

45. Bruneau M, Polivka M, Cornelius JF, George B (2005) Progression of an osteoid osteoma to an osteoblastoma. Case report. J Neurosurg Spine 3: 238-241.

46. Byers PD (1968) Solitary benign osteoblastic lesions of bone. Osteoid osteoma and benign osteoblastoma. Cancer 22: 43-57.

47. Beck SE, Schwab JH, Rosenthal DI, Rosenberg AE, Grottkau BE (2011) Metachronous osteoid osteoma of the tibia and the T7 vertebral body: a case report. J Bone Joint Surg Am 93: e73.

48. Rand JA, Sim FH, Unni KK (1982) Two osteoid-osteomas in one patient. A case report. J Bone Joint Surg Am 64: 1243. 